\title{
A Spontaneous Pneumatocele Presenting with External Auditory Canal Obstruction
}

\author{
Jinyoup Kim, Jihye Rhee, and Min-Hyun Park \\ Department of Otorhinolaryngology-Head and Neck Surgery, Boramae Medical Center, \\ Seoul Metropolitan Government-Seoul National University, Seoul, Korea
}

\section{외이도 폐쇄를 동반한 자발적 공기낭종}

김진엽 · 이지혜 · 박민현

서울대학교 의과대학 보라매병원 이비인후과학교실

\author{
Received December 28, 2015 \\ Revised March 3, 2016 \\ Accepted March 13, 2016 \\ Address for correspondence \\ Min-Hyun Park, MD, PhD \\ Department of Otorhinolaryngology- \\ Head and Neck Surgery, \\ Boramae Medical Center, \\ Seoul Metropolitan \\ Government-Seoul National \\ University, 20 Boramae-ro 5-gil, \\ Dongjak-gu, Seoul 07061, Korea \\ Tel $+82-2-870-2443$ \\ Fax $+82-2-831-2826$ \\ E-mail drpark@snu.ac.kr
}

A pneumatocele is an air-filled cavity in the body. In the head and neck areas, the extensive hyperpneumatization of the temporal and occipital bones is typically associated with pneumatocele formation, which results in the spontaneous collection of gas, usually air, beneath the pericranium or within the skull. We herein report a case of stenosis of the external auditory canal caused by a left mastoid pneumatocele in a 12-year-old boy who was successfully treated with left simple mastoidectomy and canaloplasty.

Korean J Otorhinolaryngol-Head Neck Surg 2016;59(9):692-4

Key Words Hyperpneumatization · Pneumatocele $\cdot$ Temporal bone.

\section{Introduction}

A pneumatocele is an air-filled cavity in the body that usually develops as a result of trauma, tumors, or infections caused by gas-producing microorganisms; on rare occasions, pneumatoceles can occur spontaneously. In the head and neck areas, the collection of air can be categorized as an intracranial or extracranial pneumatocele according to its location. Extensive hyperpneumatization of the temporal and occipital bones is typically associated with pneumatocele formation, which results in the spontaneous collection of gas, usually air, beneath the pericranium or within the skull. ${ }^{1)}$ We herein report a case of a left pneumatocele in a 12-year-old boy, including the clinical disease manifestation and treatment outcome.

\section{Case}

A 12-year-old boy who visited an outpatient clinic complained of swelling in the left external auditory canal (EAC). Although his mother had detected the swelling a few days earlier, the exact date of onset of the swelling was unknown. The patient did not complain of hearing loss, which would have suggested an insidious onset of the swelling. At the clinic, the patient underwent incision and drainage, resulting in the release of a small amount of serous discharge from it. After the drainage, however, the patient's mother reported that the swelling had not improved. On physical examination, the right EAC and tympanic membrane exhibited no abnormalities, but left tympanic membrane couldn't be observed due to severe narrowing of the left EAC (Fig. 1). Otorrhea, dizziness, or other symptoms were not observed. In addition, left 
conductive hearing loss was reported in the following pure tone audiometry (Fig. 2). Non-enhancing temporal bone computed tomography (CT) was performed to evaluate the EAC swelling and conductive hearing loss. The temporal bone CT scan showed a hyperpneumatized left mastoid bone and a bony cortical defect on the left side. The bony EAC wall was destroyed and filled with abnormal pneumatized air cells (Fig. 3). There was no evidence of inflammation or the presence of a tumor. The patient was diagnosed with a pneumatocele due to temporal bone hyperpneumatization and un-

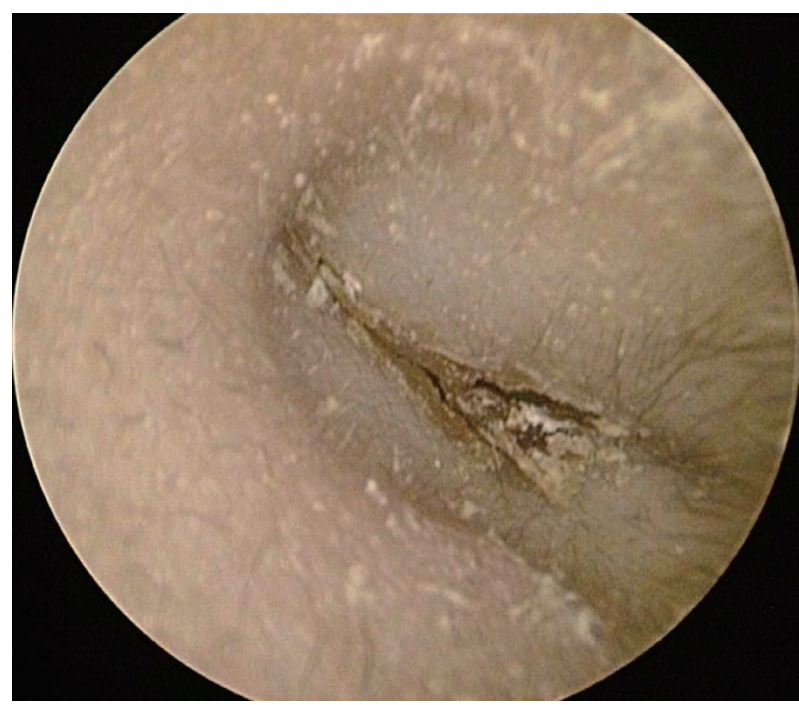

Fig. 1. Obstruction of left external auditory canal at initial examination. derwent left simple mastoidectomy and canaloplasty. During operation, cortical defect of temporal bone was found as honeycomb manner after skin flap elevation (Fig. 4). Pneumato-
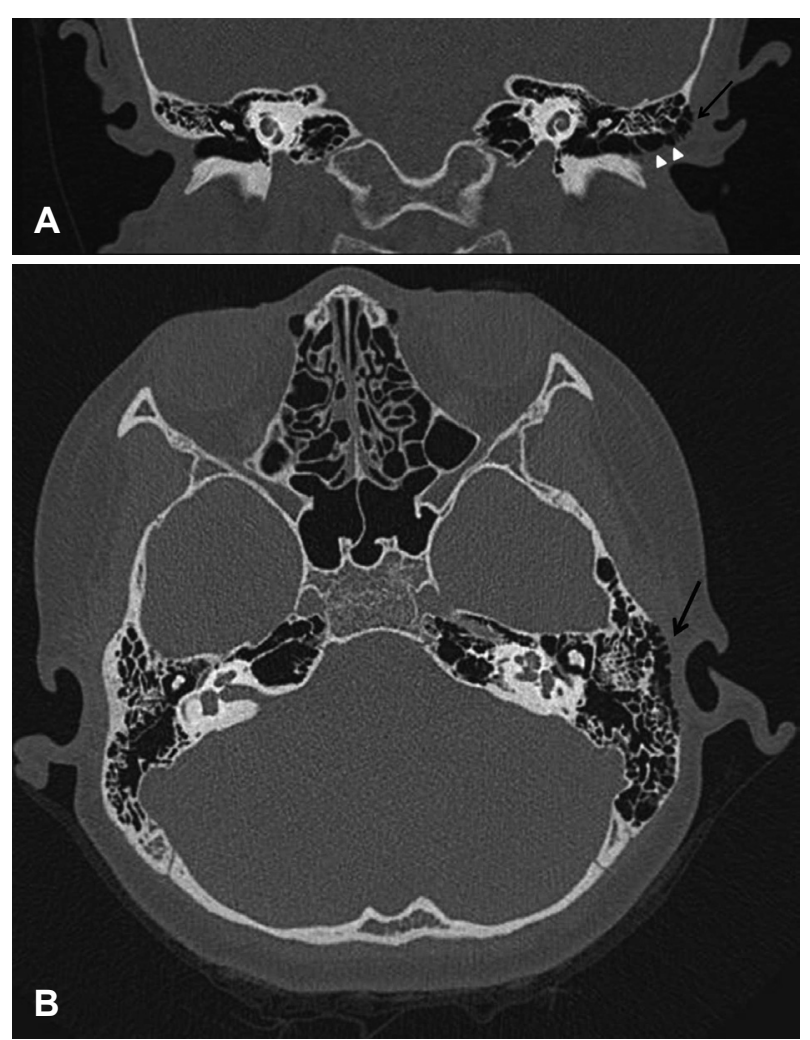

Fig. 3. Coronal (A) and axial (B) image of temporal bone CT scan (non-enhanced). Cortical defects (arrow) and pneumatocele (arrowheads) were identified.
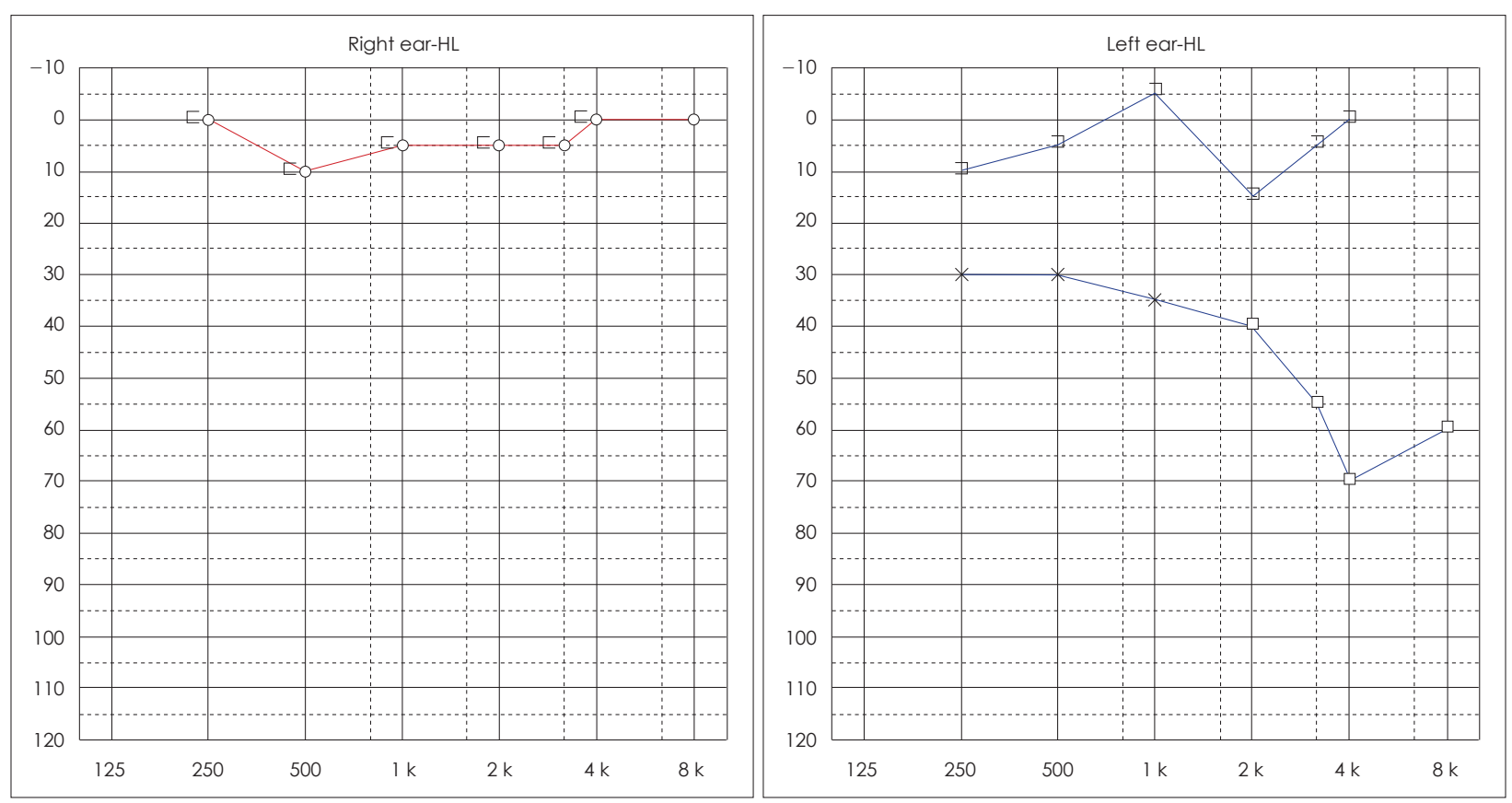

Fig. 2. Preoperative pure tone audiometry. Left conductive hearing loss was identified. 


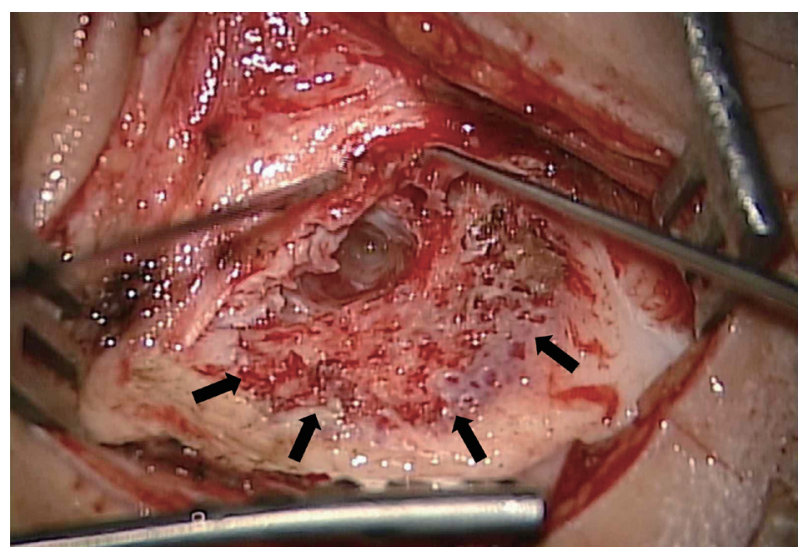

Fig. 4. Intraoperative view of hyperpneumatized area. Arrows indicate the margin of temporal bone cortical defect. In defect area, trabecular bone was shown as a honeycomb pattern.

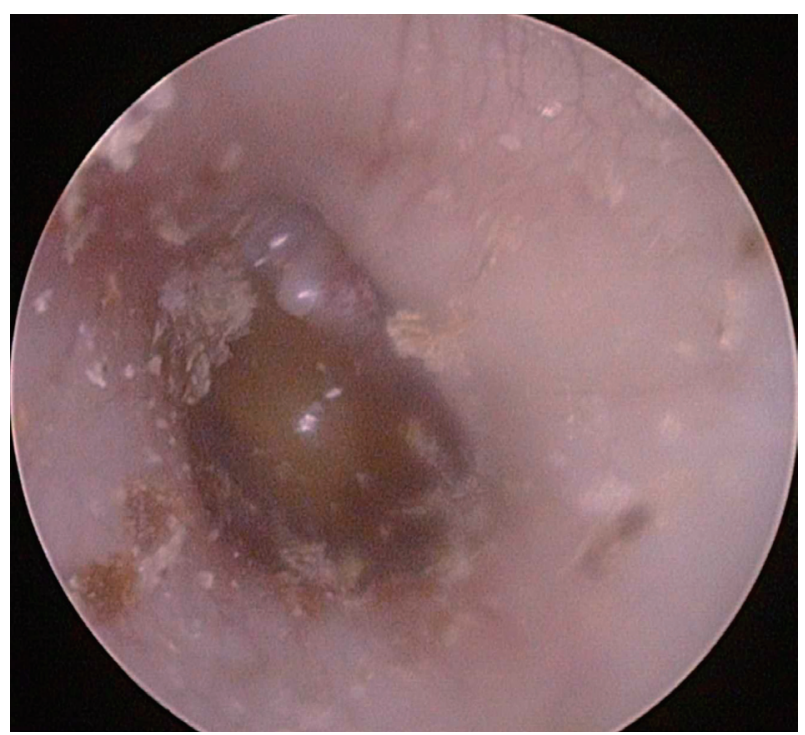

Fig. 5. External auditory canal at 1 year after canaloplasty.

cele was formed via mastoid air cell tract, so mastoidectomy was performed for removal of this defect. Hyperpneumatized bone involved posterior and superior part EAC, so these areas were drilled for smoothing and covered with skin flap. Middle ear was intact and ossicular chain was intact. He was discharged without complications. Postoperative 1 year endoscopic images were taken at the outpatient clinic (Fig. 5). EAC was intact and no showed evidence of recurrence.

\section{Discussion}

The normal process of pneumatization of the temporal bone starts in the last few weeks before birth, with a reduction of the embryonic mesenchyme in the antrum. Pneumatization progresses through infancy, childhood, and puberty, until the final portion of the petrous apex is pneumatized. ${ }^{1)} \mathrm{An}$ association between hyperpneumatization of the temporal and occipital bones and the formation of pneumatoceles has been reported. Several case reports emphasize the association of defects along the tympanomastoid and tympanosquamous suture lines with extensive hyperpneumatization of the entire temporal bone and calvarium. ${ }^{2)}$ In this case, hyperpneumatization of mastoid seems to induce a cortical defect and invade EAC as pneumatocele. Typically, a mastoid pneumatocele is found as a compressible retroauricular mass that enlarges with the Valsalva maneuver, deep breathing, or sneezing. ${ }^{3)}$ Furthermore, headaches and conductive hearing loss are typical symptoms in patients with pneumatoceles. ${ }^{1)}$ In the present case, the patient only exhibited left EAC narrowing. In most cases, noticeable hyperpneumatization is observed radiologically, and a CT scan reveals the typical honeycomb appearance with fine trabeculae, similar to that of mastoid cells. In our case, these structures were apparent in the pneumatocele, but we also observed thinning of the lateral bony wall of the mastoid. ${ }^{3)}$ In the reviewed literature, different treatment modalities have been utilized for pneumatoceles, including insertion of a ventilation tube, mastoidectomy with canaloplasty, and obliteration of the bony defect with rotation of the temporalis muscle. ${ }^{4)}$ In our case, we performed simple mastoidectomy and canaloplasty because of the wide area involved in the pneumatocele and EAC obstruction.

\section{REFERENCES}

1) Rebol J, Munda A, Tos M. Hyperpneumatization of the temporal, occipital and parietal bones. Eur Arch Otorhinolaryngol 2004;261 (8):445-8.

2) Levenson MJ, Ahuja G, Bergeron T. Spontaneous extracranial pneumatocele associated with mastoid hyperpneumatization. Arch Otolaryngol Head Neck Surg 1989;115(1):107-8.

3) Añorbe E, Aisa P, Saenz de Ormijana J. Spontaneous pneumatocele and pneumocephalus associated with mastoid hyperpneumatization. Eur J Radiol 2000;36(3):158-60.

4) Hsu CH, Chiang YC, Hsu HT, Tseng TM, Lee FP. Extracranial pneumatocele of the mastoid. Otol Neurotol 2011;32(3):e16-7. 